\title{
Recombination rate differences for pollen parents and seed parents in Pinus pinaster
}

\author{
C. PLOMION ${ }^{*}$ \& D. M. O'MALLEY $¥$ \\ $\ddagger$ NRA, Station de Recherches Forestières, BP45, 33610 Cestas, France and $\ddagger$ Forest Biotechnology Group, \\ Department of Forestry, North Carolina State University, Box 8008 Raleigh, NC 27695, U.S.A.
}

\begin{abstract}
Significantly less recombination was observed for the female gametes than for the male gametes in one individual of maritime pine (Pinus pinaster Ait.). Two segregating mapping samples of the same hybrid tree were used for genomic mapping. One sample consisted of diploid tissues from $192 \mathrm{~F}_{2}$ seedlings. The other sample consisted of megagametophytes (haploid maternally derived nutritive tissue) extracted from 156 germinated $F_{2}$ seedlings. A total of 94 RAPD markers covering 65 per cent of the genome was used for constructing the maps with both samples. Comparison for the total length of the two maps shows that meiotic recombination differs between the haploid and the diploid mapping samples. Map distances in the diploid mapping sample were on average 14 per cent larger than in the megagametophyte sample, corresponding to a 28 per cent greater rate of recombination in the pollen parent. Departure from homogeneity of recombination rate was also tested by marker interval using a likelihood-based method. Inference for greater meiotic recombination during male gametogenesis was verified analytically. A genome-wide reduction in the female gamete's recombination rate in gymnosperms presents interesting evolutionary implications, as this is exactly the opposite trend to that in the angiosperms studied so far. Direct consequences for pine tree breeding are also discussed.
\end{abstract}

Keywords: genomic map, gymnosperm, Pinus pinaster, RAPD, recombination rate, sex.

\section{Introduction}

The metric of genetic mapping is the recombination distance between marker loci, expressed in $\mathrm{cM}$. The map distances between loci can vary among individuals, between the two sexes, among related species and over environments. Beavis \& Grant (1991) showed that significant heterogeneity exists in map distances between homologous loci in different families of maize. In pea, Ellis et al. (1992) concluded that the variation in recombination rates between markers mapped in different crosses was so important that it would be difficult to construct a single map for the species. In angiosperm plants, a higher genomic map length was observed for the female in tomato (de Vicente \& Tanksley, 1991; Paterson et al., 1991; Eshed et al., 1992) and barley (Graner et al., 1991). Studies based on comparison of only a small number of gene pairs are more controversial (e.g. Robertson, 1984; Vizir \& Korol, 1990). In gymnosperms, studies based on few intervals (Moran, 1983) as well as those involving a genome-wide comparison (Groover et al., 1995) have

*Correspondence. reported a greater meiotic recombination in male vs. female gametes. The total genomic map length of interspecific hybrids has been compared with the map length for individual species (Rick, 1969; Tadmor et al., 1987; Douches \& Quiros, 1988; Gebhardt et al., 1991; Causse et al., 1994). These studies concluded that interspecific maps were approximately 25 per cent smaller than intraspecific maps. Reduced homology of the DNA strands in homologous pairs of chromosomes can be caused by differences in DNA sequence, DNA content and chromosomal rearrangements. Recombination fraction can also vary depending on the environment (Ihrke \& Kronstad, 1975; Zhuchenko \& Korol, 1983). The influence of temperature has been particularly studied and reported (Allard, 1963; Towe \& Stadler, 1964; Lu, 1974; Rose \& Baillie, 1979; Tulsieram et al., 1992). These examples of recombination differences raise several problems concerning the extent of heterogeneity and its potential impact on map merging, breeding applications, and positional cloning. If heterogeneity of recombination is common, then assembling a consensus map for a species will be difficult.

The identification of heterogeneous chromosomal 
regions requires appropriate statistical analyses of recombination data. There have been few studies reporting tests for heterogeneity of recombination rates in plants (e.g. Beavis \& Grant, 1991; Murigneux et al., 1994) and simple paired $t$-tests are often used to reveal significant differences in recombination fractions. Genomic analysis of homogeneity of recombination fraction for a whole linkage group is theoretically possible using likelihood methods. Beavis \& Grant (1991) extended Morton's (1956) test for homogeneity from two loci to many loci in a linkage group. In principle, the multilocus likelihood is calculated for each linkage group in each mapping sample, and for the pooled mapping sample. An important condition for this test is that the individual linkage maps and the pooled map must have the same markers in the same order. However, the mapping tools available (LINKAGE, Suiter et al., 1983; MAPMAKER, Lander et al., 1987; GMENDEL, Liu \& Knapp, 1990) do not calculate multilocus likelihoods for pooled data from mapping samples of different types (e.g. backcross and $F_{2}$ populations).

In this paper, we present a genomic analysis of heterogeneity of recombination fraction between two maps of the same maritime pine (Pinus pinaster Ait.) individual, constructed with haploid and diploid mapping samples. This material allowed us to infer and then compare sexually related variations in meiotic recombination. Following Fisher (1949), we used the $G$-statistics, that are related to likelihood methods, to test heterogeneity of recombination between the haploid and diploid samples for pairs of loci distributed throughout the genome.

\section{Materials and methods}

\section{Plant material, DNA extraction and amplification}

An $F_{2}$ inbred pedigree was obtained by selfing an inter-racial hybrid tree (accession 'H12') of maritime pine $(2 n=2 \mathrm{x}=24)$. Selfed seeds were germinated in 67-well format Hiko plates $(10 \mathrm{~cm}$ deep), containing a 1:2 ratio of vermiculite:peat potting mix. Megagametophytes were collected from germinated seedlings after emergence from the potting mix just before the seed coat would be cast off. Megagametophytes are mitotic derivatives of a single haploid megaspore and are derived from the same megaspore that gives rise to the maternal gamete. Therefore they are genetically equivalent to maternal gametes. After one season of growth, needles of the corresponding $F_{2}$ plants were sampled. For both megagametophyte and needle, DNA extraction was performed using the $\mathrm{CTAB}$ procedure (Doyle \&
Doyle, 1987) with some modifications described by Plomion et al. (1995a). The method of Williams et al. (1990) was used for DNA amplification. We have previously developed a strategy to choose RAPD (Random Amplified Polymorphic DNA) markers that are highly repeatable and easily scored from haploid (megagametophyte) and diploid tissue (needles of both grandparents and the hybrid parent) (Plomion et al., 1995a). These markers were also successfully amplified in the $F_{2}$ progeny. The $F_{1}$ individual tree that was mapped twice was a hybrid between the Landes and the Corsican races of maritime pine, and it was chosen because of its high selffertility. We have previously shown that $\mathrm{H} 12$ did not carry recessive embryonic lethal genes (Plomion et al., 1995a).

\section{Map construction}

Linkage relationships in the different mapping data sets were analysed with GMENDEL (Liu \& Knapp, 1990). Linkage groups were identified using a $P$-value $<0.0001$ and a minimum recombination fraction $\theta<0.40$. A first data set (haploid mapping sample) consisted of a subset of 94 RAPD markers chosen from a larger number of markers already localized on a saturated map of H12. These markers were already assayed on 124 megagametophytes of H12 (Plomion et al., 1995b). For this study, the mapping sample was extended to 156 megagametophytes. The additional 32 individuals were genotyped with these 94 RAPD markers. A second data set (diploid mapping sample) consisted of the same 94 RAPD markers assayed on $192 \mathrm{~F}_{2}$ selfed progenies of H12. Only dominant markers in coupling phase map efficiently in an $F_{2}$ population. Thus, the two linkage phases (corresponding to markers inherited from the Corsican or the Landes grandparents) were handled separately, and homologue-specific linkage groups were constructed (one to four groups per chromosome) with RAPD markers segregating 3:1 in the progeny. Because of missing data, the sample sizes used for mapping the $F_{1}$ tree varied between 124 and 156 megagametophytes and 160 and $192 \mathrm{~F}_{2}$ individuals. With these sample sizes, the linkage information was approximately equal for pairs of markers within a 30 $\mathrm{cM}$ distance. Standard errors for the estimates of recombination frequencies for both haploid and diploid mapping samples are shown in Fig. 1. A third data set, obtained by pooling the two previous data sets, was also analysed to test for departure from homogeneity of recombination fraction between the haploid and diploid mapping samples. 
Evaluation of departure from homogeneity of recombination fraction between the haploid and diploid mapping samples

Our goal was to analyse the distribution of recombination rate differences all over the genome. In particular we were interested to determine whether the male and female gametes have different levels of recombination and, if so, whether this is a genomewide phenomenon or is restricted only to certain regions of the chromosomes. Therefore, homogeneity of recombination fraction was tested for adjacent markers within each linkage group, rather than with a global test at the linkage group level. A total of 69 intervals flanked by the same markers (named according to the nomenclature used in Plomion et al., 1995b) and having the same order in the haploid, diploid and pooled maps, were tested for departure from homogeneity using the $G$-statistics obtained with the GMENDEL software. Expected genotype frequencies of the 3:1/1:1 marker configuration were added in this software, and used to compute maximum likelihood estimates of recombination fraction in the pooled mapping sample. The homogeneity test can be expressed as follows:

$G_{\text {homogeneity }}^{2}=G_{\text {diploid }}^{2}+G_{\text {haploid }}^{2}-G_{\text {pool }}^{2}$,

where the $G$-statistics are 1 d.f. tests, for independent assortment of a pair of markers in the diploid, haploid and pool maps. The statistical power of heterogeneity detection was not similar for all marker pairs, as sample sizes of the haploid and diploid progenies were not identical across the 69 intervals tested.

\section{Results}

\section{Segregation of RAPD markers}

The RAPD markers that were used in this study could be followed in the pedigree from both grandparents, through the $F_{1}$ parent, to the $F_{2}$ progeny. The segregation ratios of the RAPD markers did not depart significantly $(P<0.01)$ from the expected 1:1 and 3:1 Mendelian ratios, in the haploid and diploid mapping samples, respectively (Fig. 2).

\section{Linkage maps construction}

Dominant marker pairs contain little linkage information in $\mathrm{F}_{2}$ families when markers are in repulsion phase (trans gene arrangement) (Mather, 1936; Allard, 1956; Robinson, 1971). Thus we chose to represent the $F_{2}$ marker data as homologue-specific maps for each linkage group. Within each homologue, all markers are in coupling with respect to each other and in repulsion with respect to the markers in the complementary homologue-specific map (Fig. 3). Three linkage groups (groups 1,2 and 11 , Fig. 3) were represented by only one complementary homologue-specific map (e.g. markers inherited from the Corsican grandparent in group 2, and markers inherited from the Landes grandparent in group 11). The coverage of these groups was almost complete. For the other linkage groups, two (groups $4,8,9$ ), three (groups $3,5,6,10$ ) or four

Fig. 1 Plot of the standard error of recombination frequency for the $\mathrm{F}_{2}$ diploid mapping sample $(N=160-192$ progenies) and the $\mathrm{F}_{2}$ haploid mapping sample $(N=124-156$ megagametophytes).

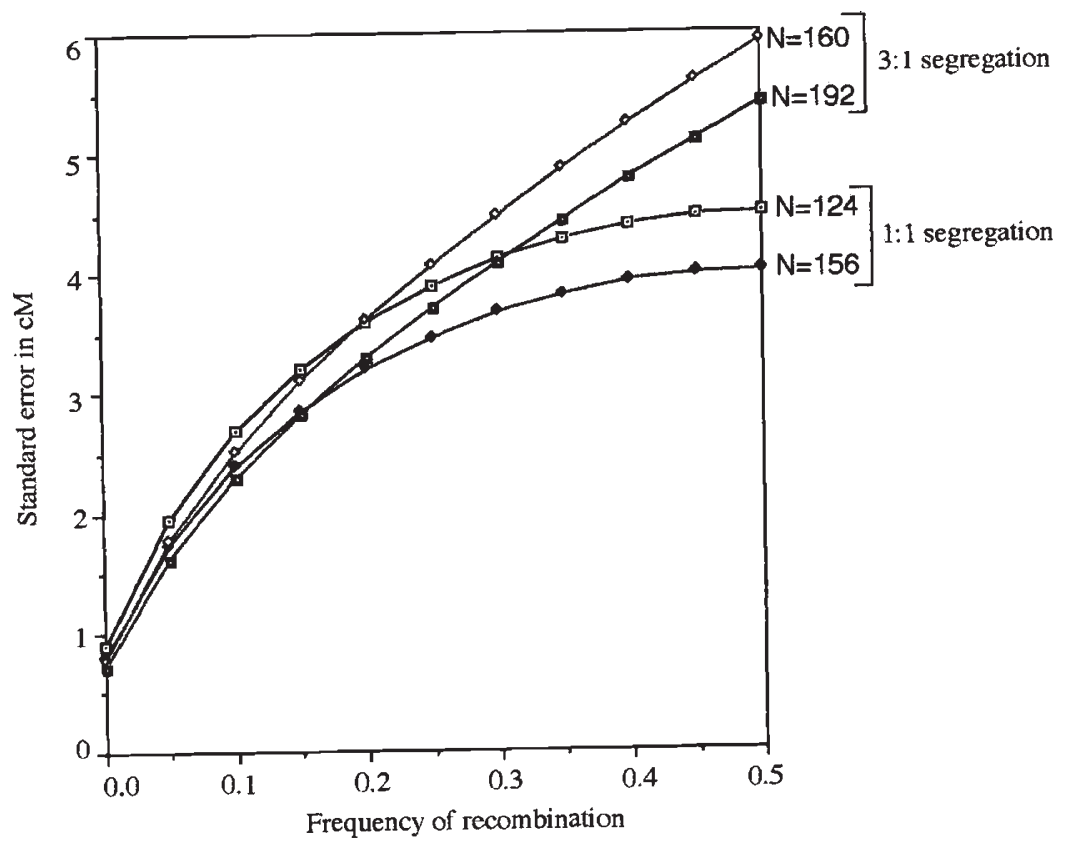

(c) The Genetical Society of Great Britain, Heredity, 77, 341-350. 
(a)

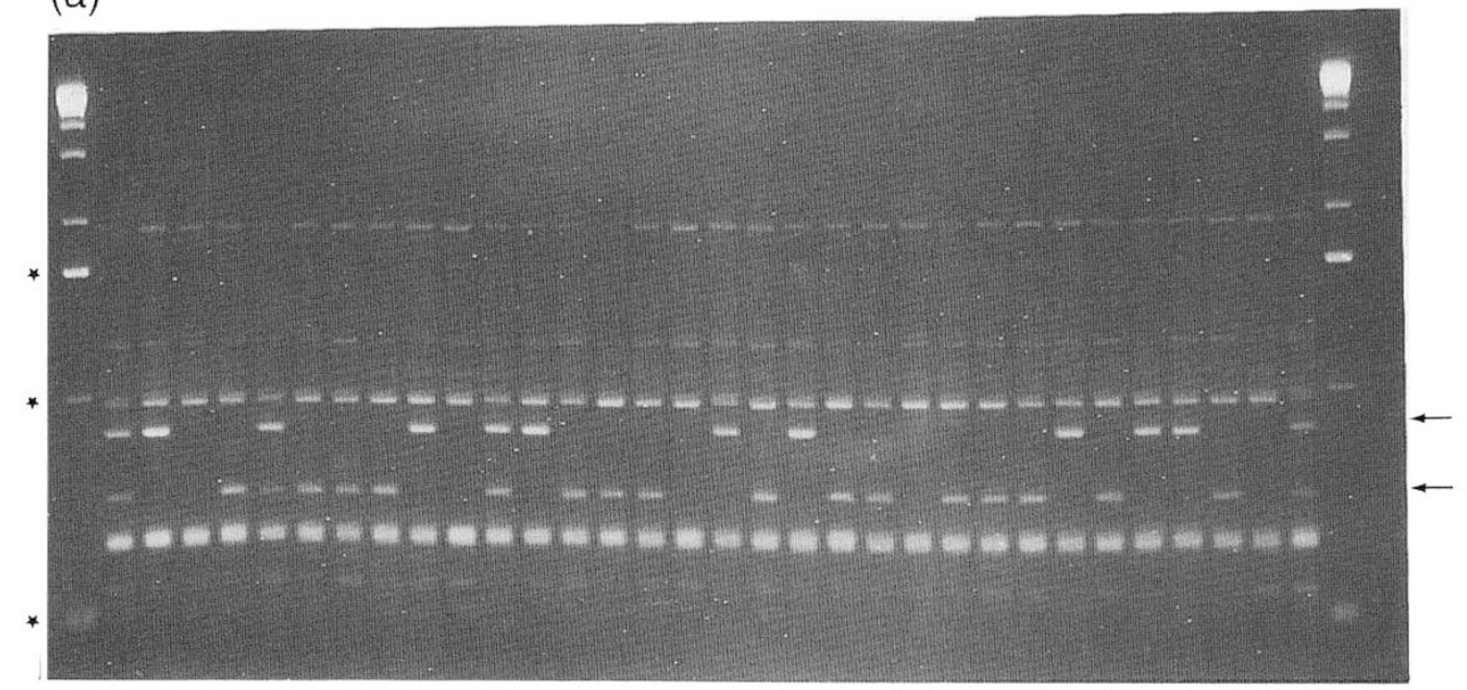

(b)

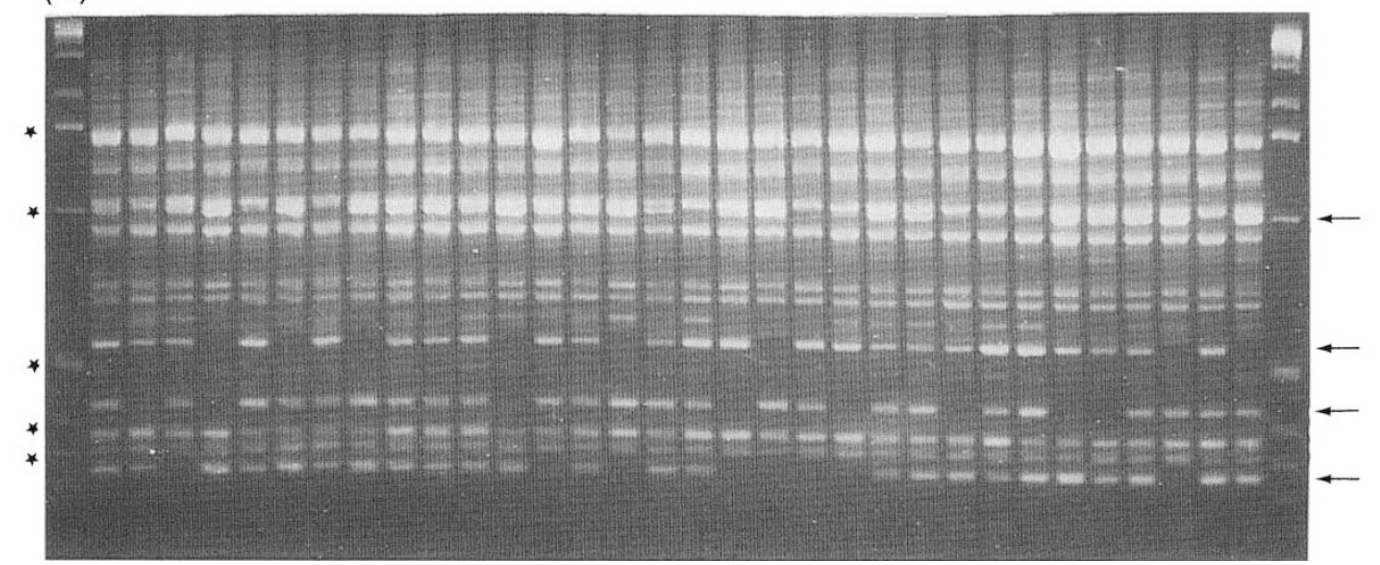

Fig. 2 Segregation of RAPD markers. Each panel shows a gel where the first and last lanes contain DNA size standards and other lanes show the separation of RAPD fragments amplified from 32 genomic DNA samples. (a) 1:1 segregation in megagametophytes amplified with OPERON primer O1 (stars from the top correspond to 1636, 1018, 510 base pairs). (b) 3:1 segregation in $\mathrm{F}_{2}$ progenies amplified with OPERON primer P10 (stars from the top correspond to 1636, 1018, 510, 396 and 298 base pairs). Polymorphic bands are indicated by arrows.

(group 7) homologue-specific maps were obtained. Linkage group 12 was not represented. The RAPDmarkers used in this study were extracted from a larger data set: 200 markers assayed on needles of the $192 \mathrm{~F}_{2}$ seedlings. Initially, these markers were chosen to maximize the genome coverage with the minimal number of RAPD reactions. However, we did not consider linkage phases in our choice, and only markers in coupling within a $50 \mathrm{cM}$ map distance could be linked. This resulted in a total of 94 RAPD markers covering approximately 65 per cent of the genome (filled region in the BC map, Fig. 3 ).

The haploid map based on previously described RAPD markers was constructed under the backcross model and was compared with the $\mathrm{F}_{2}$ map constructed from the diploid mapping sample. The RIPPLE command of MAPMAKER (Lander et al., 1987) was used to evaluate the confidence on marker ordering in both maps. Comparison of the likelihood of all permutations of adjacent triplets showed that the order of RAPD markers was at least 100 times better than any alternative order.

\section{Map comparison between the diploid and haploid mapping samples}

A comparison of meiotic recombination in centimorgans (Kosambi, 1944) for the 69 common intervals

(C) The Genetical Society of Great Britain, Heredity, 77, 341-350. 

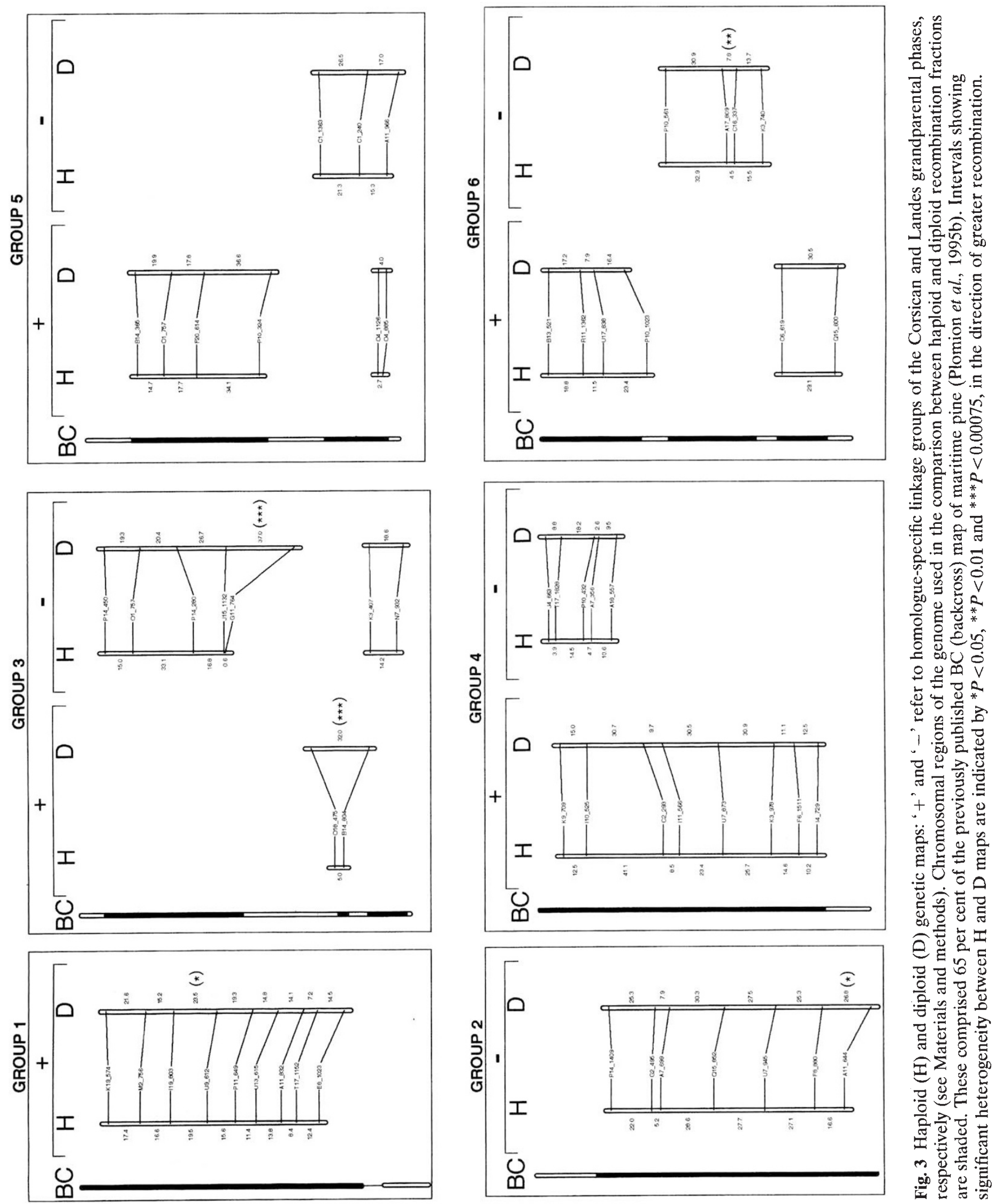

(c) The Genetical Society of Great Britain, Heredity, 77, 341-350. 

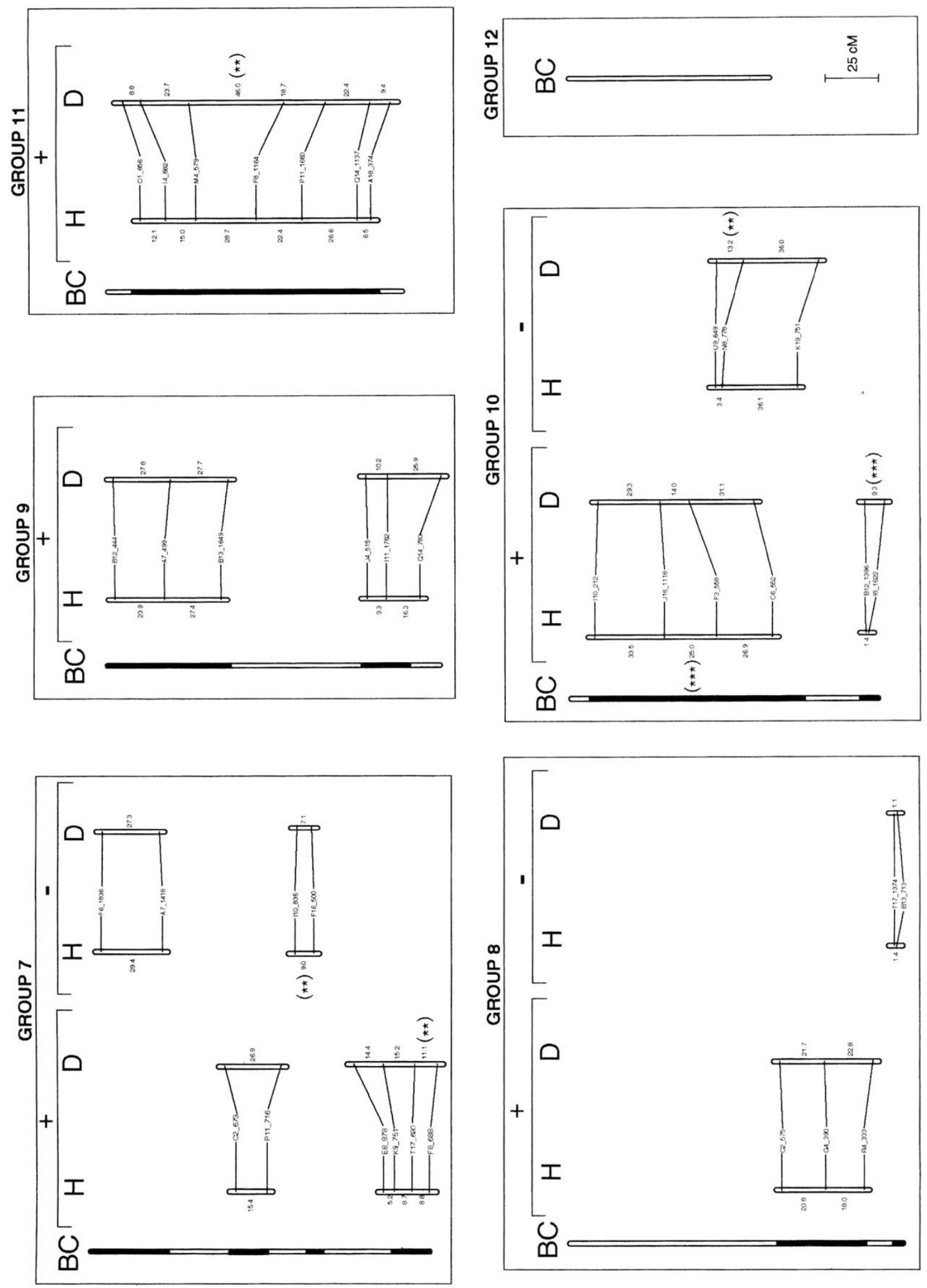

(c) The Genetical Society of Great Britain, Heredity, 77, 341-350. 
revealed an overall higher rate of recombination in the diploid than in the haploid mapping sample. A total map distance of $1169.4 \mathrm{cM}$ in the haploid map and $1354.1 \mathrm{cM}$ in the diploid map was obtained. This suggested that the map length of intervals based on the diploid tissue was on the average 14 per cent longer than for the corresponding intervals based on the haploid tissue. A paired $t$-test indicated a significant difference between the two values $(P<0.0032)$. The analysis of the 69 linkage intervals showed significant departures from homogeneity for two, five and four intervals at $P<0.05, P<0.01$ and $P<0.00075$, respectively. These heterogeneities (shown by stars in Fig. 3) were found on seven of the 11 analysed chromosomes. In most cases, the recombination rate was larger in the diploid map. However, two heterogeneities were the result of greater recombination in the haploid map (intervals [I10-F16] in group 7 with $P<0.01$, and [J16-F3] in group 10 with $P<0.00075$ ).

\section{Discussion}

Heterogeneity of recombination rate between the two maps

This study was based on recombination over map distances spanning 65 per cent of the genome of maritime pine. Considering each map interval independently, the comparison of recombination yielded significant departures from homogeneity in 11 of 69 intervals tested $(P \leq 0.05)$. However, interpretation of such a large number of tests, especially where the assumption of independence is probably violated, suggests that the type I error rate be set conservatively for genome analysis. The significance level on the whole experiment can be approximated by $\alpha \approx 1-\left(1-\alpha^{\prime}\right)^{i}$, where $\alpha^{\prime}$ is the nominal significance level for each interval, and $i$ is the number of intervals (Beavis \& Grant, 1991). For a genome-wide type I error rate of $\alpha=0.05$ and $i=69$ marker intervals, a nominal significance level of $\alpha^{\prime}=0.00075$ was obtained. Using this conservative criterion, there were four intervals with significant heterogeneity between the two maps (Fig. 3). With this very stringent threshold, we expected our genomic map comparison to yield by chance one interval with significant heterogeneity out of 1300 .

\section{Difference in male and female recombination}

In our experiment, individual effects were minimized because haploid and diploid tissues were sampled in the same individuals. Thus the genetic background of both samples was identical. In the megagametophyte mapping sample, only maternal recombination is detectable, whereas in the $F_{2}$ mapping sample both female and male gametes recombine. The difference between the maps apparently results from higher recombination frequencies in the paternal gametes. If the recombination fraction obtained from the $F_{2}$ mapping sample represents an average of the meiotic recombination rate for megaspore mother cells and microspore (pollen) mother cells, then the difference in recombination rate for megaspores and microspores should be twofold larger, i.e. approximately 28 per cent. The twofold inference between female and male recombination was analytically verified through the computation of maximum likelihood estimates of recombination fraction in male, based on prior information on female and diploid recombination. Consider two dominant markers $A$ and $B$, linked in coupling. Let $p, p^{\prime}$ and $p^{\prime \prime}=p^{\prime}+\varepsilon$ be the recombination fraction between $A$ and $B$ in the male, female and diploid tissue; respectively ( $\varepsilon$ is the percentage map expansion in diploid tissue $\varepsilon=0.14$ in our case). The frequency of the recessive phenotypic class $(a b)$ is: $(1-p)\left(1-p^{\prime}\right) / 4$ or $\left(1-p^{\prime \prime}\right)^{2} / 4$. Equating these two terms and solving for $p$ gives:

$p=\frac{p^{\prime}+2 \varepsilon-\left(p^{\prime}+\varepsilon\right)^{2}}{\left(1-p^{\prime}\right)} \approx p^{\prime}+2 \varepsilon$.

The difference in recombination rate between male and female seemed to be nonuniformly distributed on the genetic map of maritime pine. It was stronger in some intervals, absent in others, and in a few cases it was opposite to the general tendency. The same observation was reported in tomato (de Vicente \& Tanksley, 1991). In addition, no correlation was found between chromosomal regions that showed significant departures from homogeneity of recombination fraction and nearby intervals, indicating that the factor(s) involved may be specific for these regions. A significant difference $(P=0.027$ for the paired $t$-test) between both maps was obtained when only intervals showing nonsignificant heterogeneity $(P>0.5)$ were included in the analysis. This suggests a general reduction in female recombination rate throughout the genome of this species. Intervals showing significant departure from homogeneity, in particular those with $P<0.00075$, can be described as 'hot spots' of recombination.

\section{Attempt at an evolutionary interpretation for sex differences in recombination between gymnosperms and angiosperms}

In angiosperms, sexual differences in meiotic recombination rate have been reported for the whole 
genome in tomato (de Vicente \& Tanksley, 1991; Paterson et al., 1991) and barley (Graner et al., 1991). In these species, recombination rates in pollen parents were lower than for seed parents. In gymnosperms, our results are consistent with those of Moran et al. (1983) for Pinus radiata. In this species the recombination rate for pollen meiosis is approximately 40 per cent greater than for ovules. Groover et al. (1995) also reported in Pinus taeda that the genomic map length from the paternal parent was longer than the maternal map. Moran et al. (1983) attributed the differences in recombination rate to the temperature difference during megaspore and microspore formation. Indeed, in Pinus species, male and female gametogenesis occur at different periods of the season (e.g. Greenwood, 1980). In maritime pine (at a latitude of $44^{\circ} 30^{\prime}$ ), male and female gametogenesis occur in July and October, respectively (G. Philippe, personal communication). Higher temperatures could potentially increase the duration of homolog pairing and consequently increase crossover frequency in the pollen parents. However, this explanation does not provide any ultimate evolutionary interpretation.

Such an evolutionary explanation for this opposite trend in recombination rate between microspore and megaspore in angiosperms and gymnosperms could be linked to the striking differences in the reproductive biology of these taxa. Assume that recombination reduces gamete fitness, through a reduction of viability (or competitive ability) of crossover combinations, by breaking down coadapted gene complexes (Vizir \& Korol, 1990). We propose that reducing recombination frequency in microspore formation could increase fitness in angiosperms whereas reducing recombination frequency in megaspore formation could increase fitness in gymnosperms. In other words, more offspring will be produced in angiosperms if less recombination occurs in the microspore and more offspring will be produced in gymnosperms if less recombination occurs in the megaspore.

Indeed, in gymnosperms, large amounts of pollen are produced but pollen grains do not compete for fertilization of archegonia. The 'first on, first in' strategy is used (Webber \& Yeh, 1986). Abnormalities in the haploid pollen genome lead to seed abortion but the fitness of the paternal parent remains nearly intact. Soft selection eliminates unfit combinations without modifying the number of offspring ultimately produced. On the contrary, the megaspore develops into a large multicellular haploid structure, the megagametophyte. This structure serves the dual function of bearing the archegonia and of nourishing the young embryo. Food accumulation is a prezygotic phenomenon that affects fertile as well as sterile prothalli, and is therefore independent of fertilization (Maheshwari \& Sing, 1967). Too much recombination during the megaspore formation could lead to empty seeds, a resource wastage that would reduce the fitness of the maternal parent. Hard selection will lead to empty seeds, i.e. a change in the number of offspring ultimately produced.

In angiosperms, pollen grains compete for fertilization of ovules by growing through the floral tissues (stigma and style) (e.g. Mulcahy \& Mulcahy, 1987; Marshall, 1988; Sarr et al., 1988). A higher recombination may lead to a higher rate of chromosomal rearrangements that will be counter-selected in a competitive environment. In addition, aneuploidy (variation in chromosome number) is more easily transmitted through the seed parent than through pollen parents, probably because of the extremely reduced and passive female gametes. The megaspore develops into the embryo sac, a structure that is reduced in most taxa to a few cells. A general pattern is that parental provisioning of offspring (seed filling) is delayed until after fertilization (reviewed by Westoby \& Rice, 1982). Because of this postzygotic investment, abortion of the embryo sac will usually not lead to resource wastage.

Despite a difference in DNA content, plant species present on average similar chiasma frequencies. This is the case, for instance, for Arabidopsis $(0.15 \mathrm{pg} / \mathrm{C})$ and maritime pine $(24 \mathrm{pg} / \mathrm{C})$ (Plomion $e t$ al., 1995b). A comparison between angiosperms and gymnosperms is therefore justified. Hence, the differences in the reproductive biology of angiosperms and gymnosperms could explain a general reduction in recombination in the microspores of angiosperms and in the megaspores of gymnosperms. As a consequence, a lower genetic length in maps derived from female meiosis in gymnosperms and in maps derived from male meiosis in angiosperms is expected. The availability of angiosperm and gymnosperm recombination data for the whole genome is still limited and it would be interesting to confirm the apparent opposite trend in both taxa.

\section{Consequence of a greater meiotic recombination in male vs. female gametes in Pinus species}

The generation time of forest trees is very long and breeding efficiency is an important issue. Conventional breeding programmes are aimed towards obtaining favourable recombinants of linked genes. 
Depending on breeding strategies, a different rate of recombination could be desired. When favourable genes are in coupling, a low recombination may be required to recover progenies with good gene combinations, whereas increasing recombination may be preferred when favourable genes are in repulsion or when favourable and unfavourable genes are linked. Direct manipulation of genetic recombination is not yet feasible, but considering the difference in recombination fraction between the sexes, the choice of the parent with which breeding should be carried out in Pinus species constitutes an attractive substitute. As pointed out by de Vicente \& Tanksley (1991), differences in male-female recombination can potentially be exploited for practical purposes. Young \& Tanksley (1989) showed that markers can accelerate backcross breeding, and that detecting recombinant individuals that bear the genes to be introgressed with minimal amounts of flanking DNA is a critical part of the process. Our results suggest that for pine, marker-assisted backcross breeding to introgress genes from an individual into an other individual will be more efficient using the recurrent parent as the female. Linkages will be broken more easily when using the $F_{1}$ as the pollen parent.

Similarly, fine structure mapping (Paterson et al., 1990; Churchill et al., 1993) will be more efficient using meioses from the pollen parent rather than from the seed parent. In a high density map, closely linked markers will be more precisely ordered if recombination occurs more frequently. Considering the amount of DNA per cM (13 Mbp/cM in Pinus pinaster) and the high amount of repetitive DNA (Plomion et al., 1995b), positional or map-based cloning (Arondel et al., 1992; Martin et al., 1993) could be easier by using male meioses. However, in a first stage of genomic analysis, a saturated genomic map could be obtained more easily by using meioses from female gametes, because fewer markers would be required for equivalent coverage of the genome (Lange \& Boehnke, 1982).

\section{Acknowledgements}

We thank B.-H. Liu for assistance and R. Petit for helpful discussions. The RAPD work was carried out at the Forest Biotechnology Group, North Carolina State University, Raleigh. We thank R. Sederoff for inviting C.P. to conduct research in his laboratory. This research was supported by grants from INRA AIP 'Génome des Plantes Cultivées', and US Forest Service proposal no. 29-1181.

\section{References}

AllaRD, R. w. 1956. Formulas and tables to facilitate the calculation of recombination values in heredity. Hilgardia, 24, 235-278.

ALLARD, R. W. 1963. Evidence for genetic restriction of recombination in the Lima bean. Genetics, 48, 1389-1395.

ARONDEL, V., LEMIEUX, B., HWANG, I., GIBSON, S., GOOdMAN, H. M. AND SOMERVILlE, C. R. 1992. Map-based cloning of a gene controlling omega-3 fatty acid desaturation in Arabidopsis. Science, 258, 1353-1355.

BEAVIS, W. D. AND GRANT, D. 1991. A linkage map based on information from $\mathrm{F}_{2}$ populations of maize (Zea mays L.). Theor. Appl. Genet., 88, 636-644.

CAUSSE, M. A., FUlTon, T. M., CHO, Y. G., AHN, S. N., CHUNWONGSE, J., WU, K. ET AL. 1994. Saturated molecular map of the rice genome based on an interspecific backcross population. Genetics, 138, 1251-1274.

ChurChill, G. A., Giovannoni, J. J. AND TANKSLEy, S. D. 1993. Pooled-sampling makes high-resolution mapping practical with DNA markers. Proc. Natl. Acad. Sci. U.S.A., 90, 16-20.

DE VICENTE, M. C. AND TANKSLEy, S. D. 1991. Genomewide reduction in recombination of backcross progeny derived from male versus female gametes in an interspecific cross of tomato. Theor. Appl. Genet., 83, 173-178.

DOUCHES, D. S. AND QUIROS, C. F. 1988. Genetic recombination in a diploid synaptic mutant and a Solanum tuberosum $\times S$. chacoense diploid hybrid. Heredity, 60 , 183-191.

DOYLE, J. J. AND DOYLE, J. L. 1987. Isolation of DNA from fresh plant tissue. Focus, 12, 13-15.

Ellis, T. H. N., TURNER, L., HELLENS, R. P., LEE, D., HARKER, C. L., ENARD, C., DOMONEY, C. AND DAVIES, D. R. 1992. Linkage map in pea. Genetics, 130, 649-663.

ESHED, Y., ABU-ABIED, M., SARANGA, Y. AND ZAMIR, D. 1992. Lycopersicon esculentum lines containing small overlapping introgressions from $L$. pennellii. Theor. Appl. Genet., 83, 1027-1034.

FISHER, R. A. 1949. Statistical Methods for Research Workers, 11th edn. Oliver and Boyd, Edinburgh, London.

GEBHARDT, C., RITTER, E., BARONE, A., DEBENER, T., WALKEMEIER, B., SCHACHTSCHABEL, U. ET AL. 1991. RFLP maps of potato and their alignment with the homeologous tomato genome. Theor. Appl. Genet., 83, 49-57.

GRANER, A., JAHORR A., SCHONDELMAIER, J., SIEDLER, H., PILlE'N, K., FISHBECK, G. ET AL. 1991. Construction of an RFLP map of barley. Theor. Appl. Genet., 83, 250-256.

GREENWOOD, M. S. 1980. Reproductive development in loblolly pine: $\mathrm{I}$. The early development of male and female strobili in relation to the long shoot growth behavior. Am. J. Bot., 67, 1414-1422.

Groover, A. T., Williams, C. G., DEVEy, M. E., LEE, L. M. AND NEALE, D. B. 1995. Sex-related differences in meiotic recombination frequency in Pinus taeda. J. 
Hered., 86, 157-158.

IHRKE, C. A. AND KRONSTAD, w. E. 1975. Genetic recombination in maize as affected by EDTA and DMSO. Crop Sci., 15, 429-431.

KOSAMBI, D. D. 1944. The estimation of map distance from recombination values. Ann. Eugen., 12, 172-175.

LANDER, E. S. AND BOTSTEIN, D. 1989. Mapping Mendelian factors underlying quantitative traits using RFLP linkage maps. Genetics, 121, 185-199.

LANDER, E. S., GREEN, P., ABRAHAMSON, J., BARLOW, A., DALY, M. J., LINCOLN, S. E. AND NEWBURG, L. 1987. MAPMAKER: an interactive computer package for constructing primary genetic linkage maps of experimental and natural populations. Genomics, 1, 174-181.

LANGE, K. AND BOEHNKE, M. 1982. How many polymorphic genes will it take to span the human genome? Am. J. Hum. Genet., 34, 842-845.

LIU, B. H. AND KNAPP, s. J. 1990. GMENDEL: a program for Mendelian segregation and linkage analysis of individual or multiple progeny populations using log-likelihood ratios. J. Hered., 81, 407.

LU, B. C. 1974. Genetic recombination in Coprinus. IV. A kinetic study of the temperature effect on recombination frequency. Genetics, 78, 857-868.

MAHESHWAR1, P. AND SiNG, H. 1967. The female gametophyte of gymnosperms. Biol. Rev., 42, 88-130.

MARShALL, D. L. 1988. Postpollination effects on seed paternity: mechanisms in addition to microgametophyte competition operate in wild radish. Evolution, 42, 1256-1266.

MARTIN, G. B., BROMMONSCHENKEL, S. H., CHUNWONGSE, J., FRARY, A., GANAL, M. W., SPIVEY, R. ET AL. 1993. Map-based cloning of a protein kinase gene conferring disease resistance in tomato. Science, 262, 1432-1436.

MATHER, к. 1936. Types of linkage data and their value. Ann. Eugen., 7, 251-264.

MORAN, G. F., BELL, J. C. AND HILLIKER, A. J. 1983. Greater meiotic recombination in male vs. female gametes in Pinus radiata. J. Hered., 74, 62.

MORTON, N. E. 1956. The detection and estimation of linkage between genes for elliptocytosis and the $\mathrm{Rh}$ blood type. Am. J. Hum. Genet., 8, 80-96.

MULCAHY, D. L. AND MULCAHY G. B. 1987. The effects of pollen competition. Am. Sci., 75, 44-50.

MURIGNEUX, A., BAUD, S. AND BERCKERT, M. 1994. Molecular and morphological evaluation of doubled haploid lines in maize. 2. Comparison with single seed descend lines. Theor. Appl. Genet., 87, 278-287.

PATERSON, A. H., DAMON, S., HEWITT, J. D., ZAMIR, D., RABINOWITCH, H. D., LINCOLN, S. E. ET AL. 1991. Mendelian factors underlying quantitative traits in tomato: comparison across species, generations and environments. Genetics, 127, 181-197.

PATERSON, A. H., DE VERNA, J. W., LANINI, B. AND TANKSLEY, S. D. 1990. Fine mapping of quantitative trait loci using selected overlapping recombinant chromosomes, in an interspecific cross of tomato. Genetics, 124, $735-742$
PLOMION C., BAHRMAN, N., DUREL, C.-E. AND O'MALLEY, D. M. 1995b. Genomic mapping in Pinus pinaster (maritime pine) using RAPD and protein markers. Heredity, 74, 661-668.

PLOMION, C., O'MALley, D. M. AND DUREL, C.-E. 1995a. Genomic mapping in maritime pine (Pinus pinaster). Comparison of two RAPD maps using selfed and openpollinated seeds of the same individual. Theor. Appl. Genet., 90, 1028-1034.

RICK, C. M. 1969. Controlled introgression of chromosomes of Solanum pennellii into Lycopersicon esculentum: segregation and recombination. Genetics, 62, $753-768$.

ROBERTSON, D. S. 1984. Different frequency in the recovery of crossover products from male and female gametes of plants hypoploid for B-A translocations in maize. Genetics, 107, 117-130.

ROBINSON, R. 1971. Gene Mapping in Laboratory Mammals. Part A. Plenum Publishing, London.

Rose, A. M. AND BAlllie, D. L. 1979. The effect of temperature and parental age on recombination and nondisjunction in Caenorhabditis elegans. Genetics, 92, 409-418.

SARR, A., SANDMEIER, M. AND PERnES, J. 1988. Gametophytic competition in pearl millet, Pennisetum typhoides (Stapf et Hubb.) Genome, 30, 924-929.

SUITER, K. A., WENDELl, J. F. AND CASE, J. s. 1983. Linkage1. J. Hered., 74, 203-204.

TADMOR, Y., ZAMIR, D. AND LADIZINSKY, G. 1987. Genetic mapping of an ancient translocation in the genus Lens. Theor. Appl. Genet., 73, 883-892.

TOWE, A. M. AND STADLER, D. R. 1964. Effects of temperature on crossing over in Neurospora. Genetics, 49, $577-583$.

TUlSIERAM, L., COMPTON, w. A., MORRIS, R., THOMASCOMPTON, M. AND ESKRIDGE, K. 1992. Analysis of genetic recombination in maize populations using molecular markers. Theor. Appl. Genet., 84, 65-72.

VIZIR, 1. Y. AND KOROL, A. B. 1990. Sex difference in recombination frequency in Arabidopsis. Heredity, 65, 379-383.

WEBBER, J. E. AND YEH, F. C. H. 1986. Test of the first-on, first-in pollination hypothesis in coastal Douglas-fir. Can. J. Forest Res., 17, 63-68.

WESTOBY, M. AND RICE, B. 1982. Evolution of the seed plants and inclusive fitness of plant tissues. Evolution, 36, 713-724.

WILLIAMS, J. G. K., KUBELIK, A. R., LIVAK, K. J. AND RAFALSKI, J. A. 1990. DNA polymorphisms amplified by arbitrary primers are useful as genetic markers. Nucl. Acids Res., 18, 6531-6535.

YOUNG, N. D. AND TANKSLEY, S. D. 1989. RFLP analysis of the size of chromosomal segments retained around the Tm-2 locus of tomato during backcross breeding. Theor. Appl. Genet., 77, 353-359.

ZHUCHENKo, A. A. AND KOROL, A. B. 1983. Ecological aspect of recombination problem. Theor. Appl. Genet., 64, 117-185. 